\title{
Los poderes judiciales locales frente al nuevo Sistema Penal Acusatorio
}

\section{Jorge Chairez Zaragoza ${ }^{1}$}

Recibido: 27 septiembre 2016

\begin{abstract}
Resumen
La reforma constitucional en materia penal de 2008 ha generado muchas expectativas, sobre todo, en lo referente a los juicios orales. No obstante, si bien ello representa una verdadera revolución dentro del procedimiento penal, considero que no es ahí en donde se deban enfocar los esfuerzos para lograr que nuestro sistema de justicia penal sea más eficiente.

Palabras clave: Poderes Judiciales, Nuevo Sistema Penal, Juzgados, Tribunales, Sistema Acusatorio, Adversarial
\end{abstract}

\section{Local judicial powers against the new accustive criminal system}

\begin{abstract}
The 2008 constitutional reform in criminal matters has generated many expectations, especially with regard to oral trials. However, while this represents a real revolution in criminal proceedings, I believe that this is not where efforts to make our criminal justice system more efficient.

Key words: Judicial Powers, New Penal System, Courts, Courts, Accusatory System, Adversarial

\section{Sumario}

I. Introducción. II. Desafíos y expectativas del nuevo sistema de justicia penal. III. Rezago judicial. IV. Credibilidad del sistema de justicia local. V. A manera de conclusión.
\end{abstract}

\footnotetext{
1 Profesor investigador de la Universidad de Guadalajara. Miembro del Sistema Nacional de Investigadores Nivel I. jchaires@hotmail.com
} 


\section{Introducción}

Los problemas de la administración e impartición de justicia en nuestro país, como bien se sabe, son muchos y de muy diversa índole. La reforma constitucional en materia penal de 2008 ha generado muchas expectativas, sobre todo, en lo referente a los juicios orales. No obstante, si bien ello representa una verdadera revolución dentro del procedimiento penal, se requiere trabajar en otras en otros aspectos que son igualmente importantes para que nuestro sistema de justicia penal sea más eficiente.

La experiencia de otros países y de algunas entidades federativas que han implementado los juicios orales, nos demuestra que los supuestos beneficios no se percibirán en el corto plazo, muy por el contrario, todo indica que el proceso de adaptabilidad será muy largo y costoso. La responsabilidad de los estados de la República es sencillamente, esencial. Si no asumen el compromiso en serio, en la implementación del nuevo sistema penal, éste sencillamente será una quimera, si consideramos que alrededor del $80 \%$ de los delitos son del fuero común.

Dos son los desafíos que consideramos más importantes que deben enfrentar los poderes judiciales locales. Por un lado, reducir la excesiva carga de trabajo $\mathrm{y}$, por el otro, la credibilidad del los poderes judiciales locales. La gran pregunta es ¿cómo?.

Para responder a los cómos, planteamos la necesidad de que, a efecto de que se reduzca la carga de trabajo, se replanteé el principio de voluntariedad de los Medios Alternos de Solución de Conflictos y sean cada más los asuntos que se resuelvan sin pasar por las instancias judiciales. En cuanto a la credibilidad de los poderes judiciales, se propone la creación de un Consejo Nacional de la Judicatura, a efecto de que ésta sea la responsable del sistema de carrera judicial en el ámbito local.

\section{Desafíos y expectativas del nuevo sistema de justicia penal}

Una gran cantidad de estudios dan cuenta de la grave situación que se vive en nuestro país a causa de la inseguridad e impunidad. La gran mayoría de estos 
estudios se enfocan al problema a nivel federal y muy pocos estudios analizan la problemática desde el ámbito estatal y local, cuando el verdadero problema se vive precisamente en los estados y municipios.

Cabe señalar que debido a nuestro sistema federal en donde convergen dos estructuras o niveles judiciales, la federal y la de los estados de la República, resulta muy difícil hacer una evaluación integral, tanto de los problemas de inseguridad pública, procuración o administración e impartición de justicia.

Si bien la situación que guarda el poder judicial a nivel federal es muy distinta a la que se vive en las entidades federativas, y cada una de ellas, a su vez, tiene sus propias peculiaridades, existe una aspecto que es común en los dos órdenes de gobierno y que considero que es ahí en donde debemos enfocar los esfuerzos: el rezago judicial, pues ello impactará en gran medida en otros aspectos de la administración e impartición de justicia, particularmente, el que podamos cumplir con los postulados del artículo 17 constitucional de una justicia pronta y expedita, pero, sobre todo, de calidad.

Como se sabe, en el mes de junio de 2016 concluyó el plazo para que el nuevo sistema penal acusatorio entre en vigor en toda la República. El nuevo sistema acarrea retos muy importantes que debemos considerar, pero sobre todo, prever si no queremos que fracase. Del análisis a los distintos estudios realizados en América Latina, como en las entidades federativas, podemos ver que han tenido grandes dificultades para su adecuado funcionamiento, por lo que es de esperarse que su implementación en nuestro país tenga problemas similares.

El sistema acusatorio penal a través de juicios orales y medios alternativos de solución de conflictos, ha sido implementado en América Latina desde hace más de veinte años. Argentina (1991); Bolivia (2001); Costa Rica (1996); Colombia (2004); Chile (2000); Ecuador (2001); El Salvador (1998); Guatemala (1994); Honduras (2003); Nicaragua (2001); Paraguay (2000); Perú (2006) y Venezuela (1999). (Vargas; 2006; Ruíz; 2009). Además, algunos países europeos como Alemania, España, Francia, Italia, Portugal, entre otros, han implementado no sólo el sistema acusatorio y oral sino han establecido también la figura de los jurados mixtos o escabinados.

En una serie de estudios realizados en diferentes países de Latinoamérica a petición del Programa de las Américas del Centro de Estudios Estratégicos e 
Internacionales (CSIS), sito en Washington, D.C., y del Centro de Estudios de Justicia de las Américas (CEJA) con sede en Santiago de Chile, se llegó a la conclusión de que las iniciativas de reforma judicial iniciadas en Latinoamérica a partir de mediados de la década de 1990, salvo dignas excepciones como el sistema penal en Chile, el resultado general es decepcionante ya que no se satisficieron las grandes expectativas generadas, en gran parte debido a que los sistemas nuevos que funcionan de forma pobre y lenta, carecen de transparencia, prestan poca atención a los usuarios y carecen de independencia para tomar decisiones (DeShazo y Vargas, 2006), lo que se ha traducido en esos países en demoras y desperdicio de recursos, pero, sobre todo, en el desprestigio del sistema frente a los usuarios y el detrimento de la publicidad y transparencia del sistema.

Debe quedar muy claro que los juicios orales por sí solos no solucionarían los problemas de dilación, corrupción y congestionamiento que caracteriza el sistema de justicia en México. No podemos esperar que con la sola entrada en vigor de los juicios orales bajarán inmediatamente los índices de corrupción o aumentará la competitividad en nuestro país. Incluso, precisamos que al contrario de lo que se podría pensar, los países de América Latina que implementaron sistemas de juicios orales, excepto Chile, son de los países con mayor percepción de corrupción y menor cumplimiento del Estado de Derecho.

Esto no significa que el nuevo sistema no traiga aspectos positivos, es una medida que era necesaria llevar a cabo, por ser elemental dentro de un Estado que se considera de derecho. No por ello, debemos cargarle todo el peso de los problemas de la justicia penal en nuestro país al nuevo modelo. Son muchas cosas que debemos transformar todavía para que los mexicanos podamos tener una procuración e impartición de justicia digna.

Por mucho que se quiera hablar de las bondades del sistema de justicia oral, éste no traerá ningún beneficio si no se ponen en marcha otras reformas. No sólo en cuanto a la transformación de leyes, instituciones y procedimientos, sino también de prácticas y costumbres tanto de los servidores públicos como de la sociedad en general (Carbonell: 2008). Al respecto, debemos reconocer que de forma paralela a nivel nacional se está trabajando para transformar muchos de esos vicios y prácticas que están muy arraigadas en nuestro país. Por ejemplo, la creación del mando único policial; el código procesal penal único; la reforma 
educativa; el sistema nacional anticorrupción y de transparencia, entre otras.

Se debe estar consciente que las resistencias persisten y que ante cualquier problema se intentará desacreditar el nuevo sistema. Es de esperarse que en cuanto se presenten problemas derivados de la entrada en vigor, se multiplicarán las veces que pidan la vuelta al anterior sistema, particularmente de aquellos que verán afectadas sus intereses. No podemos olvidar, como lo dijimos en el trabajo anterior (Chaires, 2011), que en el caso de las reformas en materia de justicia, los beneficios no son muy evidentes, ni son corto plazo y que en la medida que la reforma es un proceso de ensayo y error, ello puede postergar y hacer menos evidentes la aparición de beneficios tangibles.

Si bien la oposición se puede encontrar en los operadores del sistema, es decir, dentro de las instituciones policiales, fiscalías y poder judicial, así también entre abogados litigantes y sociedad en general. Debemos identificar quién se beneficia con el modelo anterior de una manera ilegal, pues es aquí en donde se intentará seguir con las mismas prácticas corruptas, de tal manera que se opaquen los beneficios del nuevo sistema penal.

En un reporte del Centro de Estudios de Justicia de las América titulado "Reformas a la Justicia Criminal en Latinoamérica. Éxitos y dificultades", elaborado por Cristian Riego y Juan Enrique Vargas (2009), se señalan las dificultades que han tenido que enfrentar los países con los juicios orales, entre las que se encuentra los problemas para llevar a cabo de las audiencias: "En todos los países analizados en este proyecto resalta un mismo problema que probablemente constituye la dificultad más visible que está enfrentando el proceso de introducción de procedimientos orales. Ésta es, la generalizada ineficacia en la producción de las audiencias orales, lo que se traduce en demoras, desprestigio del sistema frente a los usuarios, desperdicio de recursos y detrimento de la publicidad y transparencia del sistema”.

Esta ineficacia en el desarrollo de las audiencias se debe según el mismo reporte, entre otras cosas, "porque en algunos países no cuentan con una agenda de juicios; en otros no se respetan las horas fijadas para el inicio y continuación de las audiencias; hay incomparecencias de los actores institucionales como defensores, fiscales, servicios periciales y jueces, incluso hasta de los imputados que se encontraban privados de su libertad, lo que ocasiona retraso incluso de 
varias horas o días; pérdida de tiempo generada por la misma desorganización de las audiencias" (Riego y Vargas, 2009).

Hay que reconocer que se han hecho esfuerzos muy importantes para dar a conocer el nuevo sistema penal y lograr su aceptación. Se han escrito muchos trabajos que analizan el nuevo sistema penal. Se han abierto un sinnúmero de cursos y seminarios para capacitar y formar a los diferentes actores involucrados. La universidades han instalado salas de juicios para la práctica de los estudiantes, entre otras medidas que han ayudado a la socialización.

Ahora bien, la participación de los estados de la república para que la reforma penal tenga éxito es fundamenta. Debido a nuestro sistema federal en donde convergen dos sistemas judiciales, el federal y el local, y en donde alrededor del $80 \%$ de los delitos son del fuero común, el éxito de la reforma recae mayormente en los estados. Así lo advierte el ministro de la Suprema Corte de Justicia de la Nación, José Ramón Cossío (2014), sobre las consecuencias del no cumplimiento de las obligaciones en los procesos penales a cargo de los estados, al poner de manifiesto que la responsabilidad de los gobiernos locales (legislativo, ejecutivo y judicial) es muy alta, al grado que de no llevarse a cabo una gran e importante cantidad de procesos de capacitación, entrenamiento, cambios normativos, adecuaciones físicas, etc., sobre un número importante de actores, la reforma fracasará. Lo cual, precisa: "la implicación de tal fracaso es tremenda, traducida en mayor impunidad, aumento de los niveles de frustración social, menor gobernabilidad y menor gobernanza, entre otros aspectos negativos".

En tal sentido, el principal reto en los estados de la República para que se vean los beneficios del nuevo sistema penal, es que dichas reformas integrales se reflejen en las instituciones locales y que, a su vez, la sociedad jalisciense las perciba. De no ser así, la perspectiva que se vislumbra es el desprestigio del sistema frente a los usuarios $\mathrm{y}$, como consecuencia, la exigencia de volver al anterior modelo. 


\section{Rezago judicial}

El primer desafío que se debe afrontar en los poderes judiciales de los estados es el rezago judicial. Un elemento sustancial para el éxito del nuevo sistema de justicia penal es el privilegiar los mecanismos alternos de solución de controversias, a fin de reducir la carga de trabajo de los juzgados y tribunales que, como se sabe, es uno de los principales problema de la administración e impartición de justicia en nuestro país. Debemos tener en cuenta que no hay ninguna institución, por muy eficiente que pueda ser, que pueda desarrollar su función de manera adecuada mientras su capacidad se vea rebasada. Este grave problema se ha querido resolver aumentando en número de juzgados y tribunales o dotándolos de más y mejor equipo, pero como ya quedó más que demostrado, ello no ha dado resultados.

Para abatir el rezago judicial los juicios orales no significan una alternativa, por el contrario pueden llegar, incluso, a colapsar el aparato de justicia. En tanto se logra implementar políticas públicas que permitan combatir la delincuencia desde su base social, de tal forma que se reduzca el número de casos que llagan a los tribunales, es necesario enfocar los esfuerzos hacia los medios alternativos de solución de conflictos, como "alternativa" para descongestionar la carga de trabajo tanto en la etapa de la averiguación previa como el proceso penal.

A pesar de las bondades que pueda traer el nuevo sistema penal acusatorio, se deben buscar alternativas para que los asuntos en los tribunales sean más bien la excepción y no la regla. Resulta paradójico que en los Estados Unidos de Norteamérica, no obstante el gran apoyo que existe a los juicios orales, la realidad es que constituye un hecho excepcional, ya que menos del 5 por ciento de los asuntos civiles y penales se resuelve en juicios orales. Prácticamente toda la maquinaria judicial está dirigida precisamente a evitar este tipo de juicios, por medio de métodos alternativos de conciliación, por los costos y la incertidumbre que representan.

Es significativo, aunque no determinante que Chile y Costa Rica que se encuentran dentro de los países con menor percepción de corrupción cuentan con el mayor porcentaje en la solución alternativa de conflictos. Costa Rica con un 
$64 \%$ de casos solucionados, Chile con $61 \%$ y muy por debajo El Salvador con 26\%; Paraguay con 10\%; Guatemala 4\%; Ecuador 2\% y la provincia de Córdoba, Argentina 1\%.

De forma paulatina las entidades federativas han ido abriendo centros o instituciones de justicia alternativa. No obstante, aunque se ha registrado un aumentó exponencial de asuntos que se tramitaron por estos medios, parece ser que se llegó a su tope, incluso en algunos casos registran una disminución, además de que el porcentaje de asuntos que se tramitan en comparación con los asuntos jurisdiccionales es muy bajo, por lo que está muy lejos de constituirse en una alternativa en la impartición de justicia y, sobre todo, como una salida al excesiva carga de trabajo de los juzgados.

En el estado de Querétaro, una de las primeras entidades federativas que incursionó en los mecanismos de justicia alternativa, al crear en el 1999 el Centro de Justicia Alternativa (prácticamente diez años antes de la reforma constitucional federal), es significativamente bajo el número de asuntos que se resuelven por esa vía. De acuerdo con el Informe de actividades del Supremo Tribunal Justicia del Estado de Querétaro 2014 - 2015, en el Centro de Mediación se registraron 4,661 expedientes y se celebraron 701 convenios de mediación, frente a 37,069 expedientes jurisdiccionales (civil, familiar y penal) y 16,886 sentencias jurisdiccionales, lo que representa aproximadamente un $12 \%$ y $4.2 \%$, respectivamente. Por otro lado, si bien el historial de asuntos que han llegado al Centro de Mediación nos refleja que hubo un aumento considerable en los primeros años (2003 y 2004), para el 2013, 2014 y 2015 la cifra de expedientes fue prácticamente el mismo, incluso hasta llegó a disminuir. Durante el periodo de 2003 - 2004, se radicaron 1,046 solicitudes; en el 2012 - 2013 ascendió a 5,327; para el 2013 - 2014 no sólo no aumentó sino que descendió a 5,300 y para el año de 2014 - 2015 se redujo aún más a tan solo 4,661 expedientes. Si bien es cierto que ello se puede deber a varios factores, como la poca difusión o la mala accesibilidad a los sistemas de justicia alternativa, lo que nos refleja es que no se está apostando a que se conviertan en una alternativa y, mucho menos, en una salida a la excesiva carga de trabajo de los juzgados.

El Centro de Justicia Alternativa de la Ciudad de México, vive una situación similar, que dista mucho de ser una alternativa. Si bien también existe 
un crecimiento exponencial, el número de asuntos es todavía muy bajo. De acuerdo con el informe de labores del Tribunal Supremo de Justicia de la Ciudad de México, en el 2007, el número de expedientes de mediación abiertos fue de 1,502 y para el 2015 de 10,058. En tanto que el total de asuntos iniciados en juzgados familiar, civil y mercantil en el 2007 fue 429,403 y para el 2015 fue de 446,829 , lo que significa que el porcentaje ronda en el $2.3 \%{ }^{2}$.

En el estado de Jalisco está pasando por la curva ascendente de las solicitudes de mediación. Para el 2012 ingresaron 8,591 y para el 2015 llegó a 12,954 asuntos $^{3}$. No obstante, se debe considerar que en Jalisco cerca del 40\% de las solicitudes de métodos alternos es por remisión judicial, es decir, no son voluntarias. El incremento de asuntos es muy importante y coincide con la baja de expedientes que se registró en los juzgados en el 2015. De acuerdo con datos del Consejo de la Judicatura en número de expedientes registrados en el 2014 en los juzgados de primera instancia en todo el estado llegó a 133,657; para el 2015 hubo un descenso al llegar a 126,781. Lo que representa un incremento en porcentaje de asuntos de mediación en relación a los juicios en los juzgados. En el 2014 era del 6\%, en tanto que para el 2015 ascendió al 10\%. Cabe señalar, por otro lado, que los 13 juzgados civiles del primer partido judicial conocieron en el 2015: 15,076 asuntos, lo que significa que se está muy cerca de que las solicitudes de mediación alcance el número de juicios civiles.

Estamos conscientes que es relativamente poco el tiempo que se ha incursionado en los medios alternativos en el país y, particularmente en el estado de Jalisco, (2011) para anticipar su fracaso. Es precisamente lo que debemos prever con trabajos de derecho comparado, para conocer la experiencia de otros países y estados de la República.

Como muestra podemos citar el caso de Argentina, en donde desde el 2005 se comenzó con la práctica de los medios alternos de solución de conflictos. A 20 años se puede decir que "no ha tenido el efecto esperado. En su estudio realizado sobre la mediación en la provincia de Córdoba Argentina, Paula Mussetta (2010), concluye que la mediación no ha tenido el éxito que se

2 Octavo informe de Labores 2015. Tribunal Superior de Justicia http://www.poderjudicialdf.gob.mx/work/ models/PJDF/Resource/3038/1/images/Octavo_Informe_de_Labores_2015.pdf 3 http://ija.gob.mx/wp-content/uploads/2015/02/Estadisticas-Generales-20141.pdf 
pretendia, y terminó siendo uno de los tantos programas deficientes e ineficaces que el gobierno puso en marcha”. Para la autora una de las inconsistencias reside en el dilema voluntariedad y/u obligatoriedad. La poca cantidad de mediaciones espontáneamente voluntarias hacen que estás terminen siendo inducidamente voluntarias o directamente obligatorias. No podemos perder de vista que en Jalisco cerca del $40 \%$ de las solicitudes de métodos alternos es por remisión judicial.

Se han dado pasos importantes para desahogar la carga de trabajo de los juzgados y tribunales, como los juicios por divorcios incausado, los juicios orales en materia mercantil y civil, sin embargo, debemos analizar la poca respuesta de la ciudadanía para acudir a solucionar sus conflictos por la vía de la mediación. Ante ello es momento para preguntarnos ¿Qué esperamos de la justicia alternativa? que se convierta en una instancia pasiva de solución de conflictos, en donde se espera que la ciudadanía se moralice y acuda voluntariamente o una verdadero mecanismo de solución de conflictos interpersonales, que se convierta no en la excepción sino la regla.

Ahora bien, uno de los problemas por los que no se ha masificado la llegada de asuntos a los medios alternos de solución de conflictos, es el principio de voluntariedad. Es decir, que la comparecencia de las partes no debe ser de carácter obligatorio, sino que debe ser voluntaria, bajo el argumento que es la esencia de la solución pacifica de los conflictos.

Diverso estudios han permitido detectar las debilidades y fortalezas de los MASC en América Latina. La experiencia de los países de la región muestran diferencias importantes entre cada uno de ellos, con problemáticas muy particulares derivadas sobre todo del mucho o poco interés y la voluntad por solucionar los problemas de administración de justicia de cada país.

Una de las principales diferencias entre los países de la región que dificulta el realizar un análisis conclusivo, es la dicotomía voluntariedad y/u obligatoriedad de los MASC. Algunos países Latinoamericanos han implementado la obligatoriedad del los MASC (Argentina, Chile, Perú, Uruguay, Colombia) ${ }^{4}$, en

\footnotetext{
4 Argentina cuenta con mediación obligatoria en diversas materias civiles desde 1995 (Ley 24.573, sobre mediación y conciliación). En Chile en la actualidad existe mediación previa (u obligatoria) en materias de familia (pública y privada), instancias de mediación en conflictos de salud, laborales, derechos del consumidor,
} 
tanto que en otros países se conciben como medios en donde las partes deben acudir voluntariamente, incluso en México, se ha considerado como uno de los principios de los MASC. Cabe señalar, que algunos países que en un inicio consideraron la voluntariedad de los MASC, han transitado a la obligatoriedad.

En un estudio elaborado por Alejandra Mera (2012) se señala que aunque todos lo países de la región cuentan con legislación y experiencias de este tipo, lo cierto es que el impacto que han tenido, tanto desde el punto de vista cuantitativo como del logro de los objetivos no han sido el esperado.

La profesora Paula Mussetta (2010). Sostiene que el mayor problema de la mediación reside justamente en su identidad, en sus fundamentos y objetivos, esto es, en la moralización. "La pretensión de desplegar junto con este programa de resolución de conflictos un proyecto de moralización social es lo que llena de paradojas, inconsistencias y ambigüedades". Para la autora una de las inconsistencias reside precisamente en esa dicotomía voluntariedad y/u obligatoriedad. Señala que la poca cantidad de mediaciones espontáneamente voluntarias hacen que estás terminen siendo inducidamente voluntarias o directamente obligatorias.

Los MASC fueron concebidos, en primera instancia, como un derecho de acceso a la justicia, especialmente a los sectores más vulnerables que no tienen los medios para acceder al sistema de justicia formal, a la vez que servirían para descongestionar la excesiva carga de trabajo de los juzgados y tribunales. Posteriormente aparecieron algunos predicadores del derecho que vieron en los MASC la herramienta ideal para la moralización de la sociedad, a través de la solución pacíficas de conflictos, ya que suponen el diálogo entre las partes a través de los acuerdos a que estas mismas arriban.

En los países de América Latina no existe un consenso sobre la voluntariedad $\mathrm{u}$ obligatoriedad de los MASC. Se dice que los medios alternos no se deben ver como mecanismos para reducir la excesiva carga de trabajo de los juzgados y tribunales, sino que deben considerarse como instrumento para fomentar la cultura de la paz y la conciliación entre la sociedad, de ahí su carácter voluntario.

un programa de justicia vecinal, etc.,. En Uruguay el art. 255 de la Constitución señala que: "No se podrá iniciar ningún pleito en materia civil sin acreditar previamente que se ha tentado la conciliación ante la Justicia de Paz, salvo las excepciones que estableciere la Ley". 
Para algunos la voluntariedad constituye la esencia de los MASC, uno de los principios que rigen su actuación.

Mauro Cappelletti y Brayant Garenth (1996), en su famoso libro Acceso a la Justicia publicado en 1978, advertían sobre las barreras al acceso a la justicia, como puede ser el costo del litigio o las diferencias entre el poder de los litigantes. Dentro de las tendencias en el uso del enfoque de acceso a la justicia, señalaron la necesidad de reformar los procedimientos generales del litigio y la creación de nuevos métodos para decidir reclamaciones jurídicas, los cuales, precisaron que estos bien podían ser obligatorios o opcionales para las partes.

"Los siguientes enfoques tienden a aceptar las limitaciones de una reforma al tribunal regular y, en consecuencia, entrañan la creación de alternativas que utilicen procedimientos más sencillos y/o decisiones menos formales. Los reformadores utilizan cada vez más, arbitrajes, conciliaciones e incentivos económicos para lograr acuerdos fuera del tribunal. Debe subrayarse que estás técnicas se pueden volver obligatorias para algunas o todas las reclamaciones, o pueden hacerse accesibles por opción de las partes (Cappelletti, y y Brayant 1996, p. 53)".

El trabajo de Alejandra Mera (2012) nos aporta elementos muy valiosos para entender la complejidad del tema de la voluntariedad o obligatoriedad de los MASC. La investigadora advierte que la incorporación de estos mecanismos, se ha fundamentado de manera importante en sus capacidades para descongestionar los colapsados tribunales de justicia. Las leyes de mediación de Argentina y Colombia surgen producto de este diagnóstico y expectativa. Incluso, resalta que la ley de los tribunales de Familia en Chile se rechazó la medición prejudicial obligatoria, pero que "al poco andar y con el colapso que sufrieron los primeros meses de instalación de los Tribunales, se llevaron adelante reformas legales que incluyeron el uso de la mediación prejudicial obligatoria, justamente como la medida idónea para enfrentar la congestión".

La autora concluye que la mediación o conciliación prejudicial obligatoria, o establecida como requisito de procedibilidad, efectivamente tiene un impacto en la descongestión de los tribunales, pero que todavía es limitado. Que en los países que la han integrado como trámite obligatorio previo para acceder a la justicia formal, el uso de los mecanismos alternativos ha aumentado de manera 
considerable. Cita el caso de Chile en done la legislación en materia de familia de 2005 incorporó la mediación como voluntaria, y en el lapso de enero-mayo 2009 ingresaron a mediación 5.772 casos. En 2008 se introdujo la mediación “obligatoria” y en el mismo período de enero-mayo de 2010 ingresan a mediación 77.661 casos. De igual manera, Perú en el 2008 reforzó la obligatoriedad de la conciliación extrajudicial y las estadísticas muestran que ha habido un aumento sostenido de casos atendidos: el año 2001, 20.000 casos; el año 2011, 75.000 causas, siendo en materias de familia este aumento mucho más notorio.

Sin embargo, destaca que en términos generales, el impacto en el sistema en su conjunto es relativamente bajo. Así, por ejemplo, en Colombia, donde existe una política pública definida de fomento de la conciliación, de los 2.700 .000 procesos judiciales activos en Colombia a 2012, solo 70.000 son sometidos anualmente a un centro de conciliación. Señala, que si bien estos mecanismos constituyen una instancia que frena la entrada al sistema judicial de un importante número de causas, por diversas razones, la mayoría de los casos susceptibles de ser resueltos por este tipo de mecanismos no terminan en un acuerdo y son susceptibles entonces de transformarse en una demanda.

De acuerdo con la Alejandra Mera (2012) ello se debe en gran medida a que un porcentaje importante de casos, la mediación o conciliación nunca llega a efectuarse por la incomparecencia de las partes, especialmente el requerido o invitado. Y precisa que las razones que explican esta circunstancia son variadas y van desde el desconocimiento y desconfianza de las personas en los MASC, como a la instalada cultura litigiosa basada en la adjudicación. A efecto de revertir esta tendencia, diversos países han adoptado medidas procesales coercitivas, como multas para quien no comparece o impidiéndole al requerido reconvenir en una eventual demanda judicial posterior. Aclara que el impacto de estas medidas no es posible de evaluar aún, pero deja de manifiesto uno de los problemas más estructurales en la implementación de MASC en América Latina. La autora considera que para una eficiente funcionamiento de los MASC en los países de la región, es necesario tomar los ejemplos de los países que muestran resultados positivos en términos de alentar la participación, como sería la instancia obligatoria o el efecto ejecutivo de los acuerdos, pero integrarlos como una oferta general que venga desde el propio sistema. 
En otras palabras, que lo "alternativo" sea el tipo de procedimiento, más que la instancia institucional en la que se ofrece. La relación entre mecanismos alternativos de resolución de conflictos y los métodos adjudicativos de la justicia tradicional debería ser articulada dentro de una estructura armónica y coherente. Ello, tanto desde el punto de vista de la eficacia y legitimidad de la justicia formal, ya que asi puede ofrecer estos mecanismos a efectos de ampliar el acceso a justicia, como para descargarse de causas, o bien, como una oferta de resolución pacífica del conflicto para quienes quieran optar por esta vía, lo que además permite traspasar costos a los particulares que pueden solventarlo. Pero también lo es desde el punto de vista de las posibilidades de los mecanismos alternativos de resolución de conflictos para posicionarse como una oferta válida y equivalente de solución al conflicto jurídico (Mera, 2012 p. 442).

\section{Credibilidad de los juzgados y tribunales del Estado de Jalisco}

Otro reto que enfrenta no sólo la nueva reforma penal sino todo el sistema de administración e impartición de justicia, radica en al legitimidad de la función jurisdiccional. Mucho se ha hablado y escrito sobre la importancia de la transparencia en el poder judicial, sin embargo su credibilidad todavía es un tema pendiente. Si bien hay que reconocer se han dado pasos muy importantes para transparentar la actuación del poder judicial, tanto federal y, aunque en menor medida, también en ámbito de local, nuestro Talón de Aquiles sigue siendo el sistema de nombramiento de los funcionarios judiciales.

Revisando la composición de los órganos de gobierno del poder judicial, en el derecho comparado podemos ver que prácticamente todos los países han adoptado fórmulas similares en su composición y atribuciones para garantizar la independencia de los jueces y magistrados, en donde concurren los tres poderes tradicionales del Estado a efecto de neutralizar en la medida de los posible las interferencias indebidas que afecten la función sustantiva de estos funcionarios.

En la composición de estos órganos del poder judicial, existe un abanico de 
opciones en el derecho comparado, aunque la tendencia que prevalece es la de órganos numerosos, de composición mixta en la que concurren los tres poderes del Estado, pero con cierto predominio de los miembros del poder judicial. Podría parecer que la existencia de estos órganos de gobierno, dada su composición mixta, contradice las posturas tradicionales del Estado constitucional liberal, al romper con el principio básico de la división de poderes. Es sabido, sin embargo, que tal principio no ha supuesto tanto una separación real, cuanto una estructura equilibrada de los mismos; no puede hablarse, pues, de contradicción, respondiendo la creación de aquellos órganos a los problemas reales y concretos con los que se enfrenta el Estado constitucional contemporáneo, que ponen de manifiesto la importancia de las funciones administrativas de los tribunales para el buen funcionamiento de la organización judicial.

Las fórmulas de integración de estos órganos de gobierno del poder judicial lo que pretenden es canalizar en un solo órgano las relaciones entre los poderes del Estado que, en términos generales, se consideran elementos básicos en las funciones de gobierno del poder judicial, en un intento de equilibrar la intervención en dichas funciones de aquellos poderes, evitando así el predominio de uno solo de ellos. No cabe duda de que la razón de esta búsqueda de equilibro se fundamenta en la valoración de aquellas funciones de gobierno y de administración, que lejos de ser consideradas como secundarias se estiman fundamentales en la garantía de la función de impartir justicia que les corresponde a los jueces y magistrados que integran el poder judicial.

El problema que esto plantea es que la participación de los tres poderes quede equilibrada, evitando los tres peligros: de preeminencia del ejecutivo, la parlamentarización y el corporativismo dentro del órgano; que influirán directamente en la función jurisdiccional de los jueces y magistrados.

En México, como se sabe, en 1994 se creó el Consejo de la Judicatura Federal, que trastocó la estructura corporativista del sistema de administración de justicia federal, permitiendo la participación de los otros dos poderes del Estado en las funciones que tradicionalmente eran exclusivas de los ministros de la Suprema Corte de Justicia de la Nación.

El Consejo de la Judicatura Federal en su composición tiene una mayor representación del estamento jurisdiccional, sobre los otros dos poderes. Esto, 
que aparentemente puede incluso, resultar lógico y deseable en algunos países, en nuestro país puede ser por el contrario altamente peligroso. México tiene una tradición de autogobierno que ha degenerado en un peligroso corporativismo y clientelismo de jueces inferiores respecto de sus superiores jerárquicos; desde el momento en que éste es uno de los mayores lastres del actual poder judicial, pareciera lógico que el Consejo de la Judicatura, llamado a terminar con esta práctica, tuviese una composición más equilibrada en relación con los otros poderes, y muy significativamente con el legislativo, que ha sido tradicionalmente el menos intervencionista en la independencia del poder judicial federal.

No obstante, a poco más de 20 años de la creación del Consejo de la Judicatura Federal existe una percepción, (podemos decir muy amplia) por parte de los usuarios del servicio (abogados litigantes), de que el poder judicial federal ha podido consagrar una muy importante credibilidad en el ejercicio de su desempeño; aunque hay, por supuesto, quienes no estén de acuerdo con ello y opinan todo lo contrario, lo cual tiene que ver especialmente en experiencias particulares que tienden a generalizar el servicio.

En el Estado de Jalisco ya experimentamos con distintos mecanismos para la selección de los funcionarios del poder judicial, ya sea por la designación directa por parte de los magistrados del Supremo Tribunal de Justicia o una supuesta carrera judicial bajo el control del Consejo de la Judicatura, y la realidad es que ha sido un rotundo fracaso.

Uno de los problemas que se perciben es que el Congreso elige a los consejeros, introduciendo un componente político-partidista dentro del poder judicial, que deriva en consecuencia en un órgano politizado y altamente deslegitimizado que se proyecta directamente a la actividad jurisdiccional, por lo que se sigue pensando que los nombramientos de los funcionarios responde a un reparto de cuotas entre diputados, magistrados, consejeros, partidos políticos, incluso, entre los poderes fácticos del estado (iglesia, universidades, sindicatos, etc.).

Coincidimos con Loewenstein (1986), quien considera que el problema es sobre todo "socio-psicológico"; es decir, el detentador de un cargo permanece obligado a la persona responsable de su nombramiento, por lo que la designación contiene peligros específicos en el caso de la función judicial. Especialmente 
cuando el nombramiento está determinado por consideraciones políticas, pues el favorecido está expuesto a la tentación humana de pagar su deuda desempeñando su cargo de forma condescendiente.

Es claro que el modelo de un órgano del poder judicial, que a nivel federal y en otros países sí ha funcionado, en los estados ha sido un rotundo fracaso. Y su fracaso no es otro que los cargos dentro del poder judicial se consideran como botín político. Como bien se sabe, las prácticas del amiguismo, compadrazgo, nepotismo y el pago por los oficios prestados durante las campañas electorales, siguen siendo los criterios que privan a la hora de nombrar a los funcionario del poder judicial del Estado. A pesar de la existencia del Consejo de la Judicatura del Estado de Jalisco y que la ley contempla el sistema de carrera judicial, éstas no se ponen en práctica. Los partidos políticos siguen blindando el feudo en donde se nutre y recompensa la lealtad partidaria, con un gran número de cargos en la administración de justicia, lo que explica que ningún partido tenga el real interés de implementar el servicio civil de carrera judicial a nivel local.

Los distintos actores políticos del estado se reparten las plazas para agradecer los favores recibidos. Tanto los diputados, los partidos políticos, el gobernador y demás actores no van a querer perder el control del poder judicial. Y no nos engañemos, no lo van a hacer. Resulta ilusorio pensar que con el sistema actual de manera milagrosa se terminen con esas prácticas. Mucho menos, si volvemos al antiguo modelo corporativista a cargo del Supremo Tribunal de Justicia. ¿Qué esperamos entonces? ¿Cuáles son las opciones qué nos quedadan?.

La participación ciudadana es, probablemente, nuestra última oportunidad para lograrlo si no queremos que el estado pierda la soberanía de la carrera judicial. La creación de un consejo ciudadano o la participación de organizaciones de la sociedad civil, universidades, colegios de abogados, etc., se vuelven una alternativa que deben ser analizadas y valoradas. Si bien, cada una de estos mecanismos conlleva ciertos riesgos o defectos, se debe ponderar si son mayores a los que se viven actualmente.

De no hacerlo, tendremos que buscar tarde o temprano alternativas que van más allá de nuestra tradición jurídica. Por un lado, el ceder el manejo de la carrera judicial a una instancia nacional, como se ha hecho ya en materia electoral, educativa o de transparencia; es decir un Consejo Nacional de la 
Judicatura. Si bien, ello va en contra del sistema federal lo cierto es que la culpa es de los estados de la República, que en 200 años no han sabido o no han querido contar con un poder judicial independiente y, sobre todo, eficaz. Por otro lado, el jurado popular, una institución que si bien por cultura jurídica no nos agrada e históricamente la hemos repudiado, debemos considerar que ya ha sido implementado en países europeos con tradición jurídica del civil law, como Alemania, España, Italia o Bélgica. Hay que recordar que tanto Aristóteles como Montesquieu, eran partidarios de los jurados no permanentes, como mecanismo para evitar el despotismo y la corrupción del juez profesional o funcionario.

\section{Conclusiones}

a) Conscientes de que el éxito del nuevo sistema penal, sobre todo, en cuanto a los juicios orales, depende de la implementación de una serie de reformas complementarias, las cuales ya se han comenzado a poner en marcha, a nivel nacional, como el mando policial único, la unificación de los códigos penales, el sistema nacional anticorrupción, así como el de transparencia, entre otras, el reto para el estado de Jalisco es que dichas reformas se reflejen en las instituciones locales y que, a su vez, la sociedad jalisciense las perciba. De no ser así, la perspectiva que se vislumbra es el desprestigio del sistema frente a los usuarios y, como consecuencia, la exigencia de volver al modelo anterior.

b) Si bien es cierto, se han hecho esfuerzos muy importantes para la puesta en marcha del nuevo sistema penal, como trabajos de análisis y reflexión, cursos y seminarios de capacitación, salas de juicios orales en las universidades, entre muchas otras, el reto será que el tener la capacidad para ir corrigiendo las fallas y errores que, invariablemente, se irán presentando, por lo que resulta necesario y oportuno el crear una instancia permanente y autónoma que monitoreé la puesta en marcha del nuevo sistema penal acusatorio en el estado de Jalisco. Un laboratorio que lleve a cabo un seguimiento y evaluación de las 
diferentes instituciones involucradas. Que analice las condiciones en las que se está laborando. Que determine si se cumple con las disposiciones normativas relativas al sistema acusatorio. Que vigile el que no se siga con los vicios y las viejas prácticas inquisitorias, etc.

c) Un elemento sustancial para el éxito del nuevo sistema de justicia penal son los mecanismos alternos de solución de controversias, en la medida que sean una alternativa para reducir la carga de trabajo de los juzgados y tribunales. Si bien se ha avanzado mucho en la implementación de dichos mecanismos, es momento de hacer un corte de caja y analizar si se han cumplido con los objetivos propuestos (si es que se plantearon). Ante la poca respuesta de la ciudadanía para acudir a solucionar sus conflictos por la vía de la mediación, es momento de cuestionarnos si esas eran las expectativas esperadas. Es momento para preguntarnos ¿Qué esperamos de la justicia alternativa? que se convierta en una instancia pasiva de solución de conflictos, en donde se espera que la ciudadanía se moralice y acuda voluntariamente o un verdadero mecanismo de solución de conflictos interpersonales que se convierta no en la excepción sino en la regla.

d) La propuesta es eliminar el principio de voluntariedad contemplado en la Ley de Justicia Alternativa, como ya lo están haciendo en otros países de América Latina, para "forzar" a que cada vez sean más los casos que se arreglen mediante los MASC, y de esta forma verdaderamente descongestionar el sistema de justicia en el Estado de Jalisco.

e) Otro reto que enfrenta no sólo la nueva reforma penal sino todo el sistema de administración e impartición de justicia radica en la credibilidad de la función jurisdiccional. Es imprescindible que se transparente la selección de los funcionarios judiciales, a través de la participación ciudadana. La creación de un consejo ciudadano o la participación de organizaciones de la sociedad civil, universidades, colegios de abogados, etc., se vuelven una alternativa que deben ser analizadas y valoradas. De no hacerlo, tenderemos que buscar, tarde o temprano alternativas que van más allá de nuestra tradición jurídica, como puede ser la creación de un Consejo Nacional de la Judicatura, como instancia 
responsable de la carrera judicial en los estados o la implementación del jurado popular, como ya lo hicieron prácticamente todos los países europeos con tradición jurídica del civil law.

\section{Bibliografía}

Cappelletti Mauro. (1996). Acceso a la Justicia. La tendencia en el movimiento mundial para hacer efectivos los derechos. México, FCE.

Carbonell, Miguel. (2008). "La reforma al sistema penal: elementos para un diagnóstico". Revista de la Facultad de Derecho de México. UNAM, Tomo LVIII. Número 250. Julio-diciembre, pp. 11-29.

Cossío Díaz, Ramón. (2014). "La reforma judicial penal en las entidades federativas". Las reformas y los Estados, la responsabilidad de los Estados en el éxito de los cambios estructurales. México, IMCOChaires Zaragoza, Jorge. (2011). "Sistema acusatorio versus sistema inquisitorio". Iter Criminis

DeShazo, Peter y Vargas Vivanco, Juan Enrique. (2006). Evaluación de la Reforma judicial en América Latina. CEJA.

http://www.cejamericas.org/doc/documentos/JudicialReforminLatinAm eri ${ }^{\circ}$ caSPANISH final.pdf

Fix-Fierro, Héctor, (2007). La Jornada, 29 de agosto.

http://www.jornada.unam.mx/2007/08/29/index.php?section=politica\&a $\underline{\text { rticle }=021 \mathrm{n} 1 \mathrm{pol}}$

Loewenstein, Karl. (1986) Teoría de la Constitución. $2^{\mathrm{a}}$ ed. trad. de Alfredo Gallego Anabitarte, Barcelona, Ariel.

Mera, Alejandra. (2012). Mecanismos alternativos de solución de conflictos en América Latina. Diagnóstico y debate en un contexto de reformas.

http://w1.cejamericas.org/index.php/dialogo-nueva-justicia/mediosalternativos-de-conflicto.html 
Mussetta, Paula. Entre el derecho y la moral. Un análisis de la mediación como estrategia para la resolución de conflictos. México, UNAMFLACSO.

Riego, Cristian y Vargas, Juan Enrique. (2009). "Reforma a la Justicia Criminal en Latinoamérica. Éxitos y dificultades". Centro de Estudios de Justicia de las América. Centro de Estudios de Justicia de las Américas (CEJA).

Ruiz Torres, Humberto Enrique. (2009). "La implementación del sistema de justicia oral: éxitos y fracasos". Inter Crimines. Revista de Ciencias Penales. México, Instituto Nacional de Ciencias Penales. Número 10, Cuarta Época. pp. 75-116.

Solís Delgadillo, Juan Mario. (2009). "La reforma penal mexicana, espejismos y realidades. Los actores del sistema como variables de éxito o fracaso". Reforma Judicial. Revista Mexicana de Justicia. Número 13 Enero-Junio Año 2009, pp. 95 - 116.

Vargas Vivanco, Juan Enrique. (2006). "La nueva generación de reformas procesales penales en Latinoamérica”. Ponencia presentada al Congreso Internacional de Derecho Penal - VII Jornadas sobre Justicia Penal, organizado por la Universidad Autónoma de México. Ciudad de México. 
